\title{
SECONDARY METABOLITES CHANGE UNDER VERNALIZATION AND ITS RELATION TO FLOWERING COMPETENCY IN SHALLOT (Allium cepa var. aggregatum)
}

\author{
M. Marlin ${ }^{1, *}$, A. Maharijaya ${ }^{2}$, A. Purwito ${ }^{2}$ and S. Sobir ${ }^{2}$ \\ ${ }^{1}$ Department of Crop Production, Faculty of Agriculture, University of Bengkulu, Indonesia \\ ${ }^{2}$ Department of Agronomy and Horticulture, Faculty of Agriculture, Bogor Agricultural \\ University, Indonesia \\ *E-mail: marlin@unib.ac.id
}

\begin{abstract}
Shallot extract contains a great quantity of essential oil, volatiles, and other compounds. The composition of a secondary metabolite can be regarded as the ultimate reactions of biological and physiological to genetic and environmental conditions. This study was objected to identifying metabolomic composition and its relation to flowering competency in 5 genotypes of shallot. The non-targetted metabolites were identified using GC-MS and assigned by matching their mass spectra with those available in the WILEY7 LIB. Data matrix was analyzed by using a metabolomic package of the $\mathrm{R}$ software. Heatmap was visualized for a total of 130 of metabolites in non vernalized bulbs and 122 of metabolites in vernalized bulbs of 5 shallot genotypes. The composition metabolites from 5 genotypes were the difference and suggested correlated to flowering competency. The 3 genotypes of flowering type of shallot produced the highest concentration of phytol (ditherphene alcohol) and low concentration of nitrogen compound. Whereas, 2 genotypes of non-flowering types contained a high concentration of organosulfur and nitrogen sources. Metabolite profile of 5 genotypes contained volatile and non-volatile phytonutrients, vitamin, saturated fatty acid and organosulfur compounds.

Keywords: Dissimilarity Matrix, GC-MS, Non-targetted Metabolite, Organosulfur, Phytol
\end{abstract}

(C) RASĀYAN. All rights reserved

\section{INTRODUCTION}

Shallot (Allium cepa var.aggregatum) is an important Allium plant that been used for food, ornamental, natural alternatives to food synthetic preservatives and medicinal for curing various diseases. Allium plants contain different sugars, amino acids, vitamins, sulfurous compounds, enzymes, flavonoids, saponins and minerals ${ }^{1}$. Allium is also valued for their therapeutic properties; they are active as diuretics and laxatives and have been used to treat headaches and parasitic worms ${ }^{2}$. Onion has a beneficial effect as their prebiotic, and their ability to decrease levels of insulin, cholesterol, triacylglycerol and phospholipids for human health ${ }^{3}$, and considered an important vegetable and medicinal plant prescribed as an effective therapy for several complaints in healing treatment such as natural cancer treatment ${ }^{4}$. These beneficial effects will become an important target in shallot breeding and management practices. Shallot genotypes may vary in flowering pattern, naturally flowering, inducible flowering, and noninducible flowering shallot ${ }^{5}$. Flowering in shallot can be induced by an exogenous treatment such as vernalization. Vernalization is an important adaptation of plants to initiate flowering in response to prolonged exposure to low temperatures ${ }^{6,7}$. The principles derived from vernalization are likely to be widely relevant to epigenetic reprogramming in many organisms ${ }^{7}$. External condition plays an important regulation in plant bioactivity and influences the metabolomic composition. Metabolomic composition in the plant is various and specific, that depends on genetic and plant growth environment. Metabolomic describes plant phenotype differentiation. Metabolomic technologies have revealed new insights in biological systems through metabolic dynamics ${ }^{8}$. The metabolomic composition determines the biological

Rasayan J. Chem., 12(3), 1418-1425(2019)

http://dx.doi.org/10.31788/RJC.2019.1235356

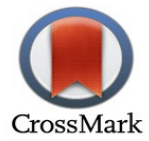


and physiological function of the plants. Metabolite compounds are observed in the 6 Alliaceae family ${ }^{9}$, in Allium cepa (onion) extracts ${ }^{10,11}$, in Allium rotundum $\mathrm{L}^{12}$, in Allium sativum (garlic) formulations ${ }^{13,14}$, and in shallot grown in tidal swampland ${ }^{15}$. Metabolomic defined as a comprehensive analysis in which all the metabolites of a biological system are identified and quantified ${ }^{16}$. Metabolites are the end products of cellular regulatory processes. Metabolites profiling in plants can be directly extracted from a part of plantthe to find new molecules contents. Profiling of the metabolite composition is an important way to evaluate the contents of the medical plants, as well as their safety and efficacy ${ }^{17}$.

Mass spectrometry is an analytical method, which allows the determination of the mass formula and structure. With mass spectrometry, individual molecules can be measured based on their molecular peak $(\mathrm{m} / \mathrm{z})$ and characteristics spectra of fragment ions ${ }^{18}$. Mass spectrometry technology is high sensitivity to identify the unknown and unexpected of the components present in the complex biological samples ${ }^{19}$. These fragments often provide a clue to the molecule's structure, but without a reference compound, the difficulty of making an identification increases markedly ${ }^{18}$. The analytical strategy gase chromatography mass spectrometry (GC-MS) used to analyze the volatile compounds, and selected compounds were structurally measured by mass spectrometry transposing the method to GC-MS ${ }^{20,21}$. The mass analyzer separates the molecules or/and fragments according to their masses and the detector detects and quantifies the separated ions ${ }^{18}$. GC-MS analysis is performed on single-quadrupole mass spectrometers, which provide nominal-mass information. Quadrupole MS spectra can be easily compared with commercial or inter-laboratories databases ${ }^{19}$.This study $\mathrm{w}$ as objected to identify secondary metabolite composition and its relation to flowering competency in 5 genotypes of shallot.

\section{Plant Materials}

\section{EXPERIMENTAL}

Local genotypes of shallot with a different pattern of flowering were selected as plant material. Shallot genotype 'Bentanis' is used as the naturally flowering, while genotypes 'Bima Brebes Ilokos, Tajuk and Sumenep' are selected as the induced flowering of shallot ${ }^{5}$. Experiments were planted in Pasir Kuda research farm, Bogor Indonesia. Each genotypes were treated with vernalization in $8^{\circ} \mathrm{C}$ temperature for 5 weeks, and no vernalization treatment as control.The bulbs were then planted in $45 \mathrm{~cm}$ diameter polythene bags containing $8 \mathrm{~kg}$ of growing media (soil: manure: husk =2: 1: 1). Each polybag was planted with three bulbs. Before planting, shallots bulbs were soaked in a fungicide benomil 50\% at a concentration of 2 g. $\mathrm{L}^{-1}$ for 15 minutes. The bulbs were then soaked into solution of plant growthpromoting rhizobacteria of 5 g.L $\mathrm{L}^{-1}$ for 15 minutes. NPK fertilizers with a ratio of 15:15:15 were applied in a dose of $600 \mathrm{~kg} \cdot \mathrm{ha}^{-1}$ or $2.4 \mathrm{~g}$ per polybag.

\section{Metabolomic Analysis}

The samples were the leaves of shallot plants at 4 weeks after planting (bolting stage). Leaves were cutted for $10 \mathrm{~g}$ and were extracted with methanol $(50 \mathrm{~mL})$. The methanolic extract of shallot leaves were used as a sample in the GC-MS analysis. GC-MS unit was carried out on an GCMS-QP2010 system (Shimadzu Corporation, Japan) coupled to mass a spectrometer detector. The samples were inserted into the quartz chamber in the GC-MS unit. Helium was used as a carrier gas in a constant flow mode at $0.85 \mathrm{ml} / \mathrm{min}$. The chamber was heated in an oxygen-free environment at a temperature of $400^{\circ} \mathrm{C}$ for 0.2 minutes. The reaction will produce heat-mediated cleavage of chemical bonds in the macromolecular structure and produce low molecular weight with a chemical composition that identify specific compound of metabolite. Compound mixtures were then passed through the column GC-MS analysis. The column is Rt x $5 \mathrm{MS}$, with length $60.0 \mathrm{~m}$, thickness $0.25 \mu \mathrm{m}$, and diameter $0.25 \mathrm{~mm}$. The initial temperature of the column was $50{ }^{\circ} \mathrm{C}$, which was gradually increased by $10{ }^{\circ} \mathrm{C}$ up to $280{ }^{\circ} \mathrm{C}$. At the end of this period, the column oven temperature was $50{ }^{\circ} \mathrm{C}$ raised up to $280{ }^{\circ} \mathrm{C}$. Injection port temperature was ensured as 280 ${ }^{\circ} \mathrm{C}$ and helium flow rate as $0.85 \mathrm{ml} / \mathrm{min}$. Mass spectrometer detector was employed to detect compounds when they were vented from the column. Temperature of the detector was $200{ }^{\circ} \mathrm{C}$. Secondary metabolites of the plant samples were then identified for each treatments.

The identification of the components of the non-targeted metabolite was assigned by matching their mass spectra with those available in the WILEY7 LIB. The metabolitecompounds of the plant samples were 
then identified for each genotypes. Spectra were compared with National the Institute of Standard and Technology (NIST, 2005 v2.1) library to identify the unknown compounds. The data were confirmed using PubChem online database in National Center for Biotechnology Information (https://pubchem.ncbi. nlm.nih.gov/), chemicalbook database (http://www.chemicalbook.com), and NIST webbook database http://webbook.nist.gov/. The datasets had been transformed to $\log 2$ and meancentered in order to acquire the normalized data. Data matrix based on non-targetted metabolomic of shallot in each vernalization treatments were analyzed using Metabolomic package of the $\mathrm{R}$ software ( $\mathrm{R}$ version 3.2.2 http://www.r-project.org/). Metabolomics package was operated to construct HCA (hierarchical cluster analysis) and visulized heatmap with dendrogram. HCA was performed using Euclidean distance method and complete linkage agglomerative method.

\section{RESULTS AND DISCUSSION}

A total of 130 of metabolomic of non-vernalized bulbs, and 122 of metabolites of vernalized bulbs of 5 shallot local genotypes were identified by GC-MS. Metabolite compound obtained where then visually described by metabolite heatmap (Figure-1). Heatmap is widely used in metabolomic research because it is able to visualize large amounts of metabolite data and its differences in sample groups ${ }^{22}$. Heatmap of both non vernalized and vernalized bulbs clustered 5 shallot local genotypes into three groups (Figure-1). First group was G2 (Bima Brebes genotype) and G4 (Tajuk genotype), second group was G1 (Bentanis genotype), and the third group was G3 (Ilokos genotype) and G5 (Sumenep genotype).

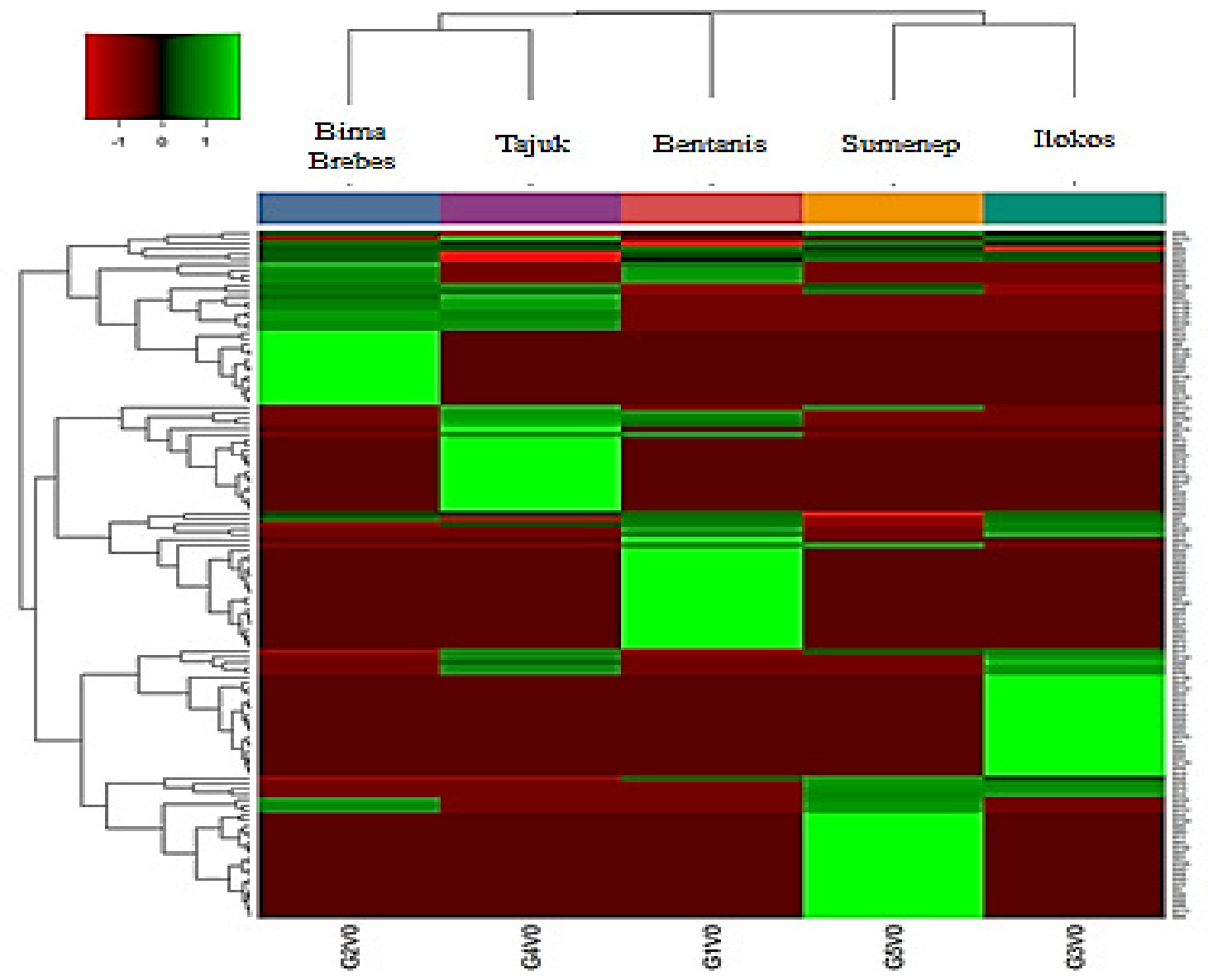

Fig.-1: Heatmap of hierarchical clustering analysis based on non-targeted metabolomic in 5 shallot genotypes of 130 metabolites in non-vernalized bulbs. Color-coded matrix represents the mean values of the metabolite intensity in 5 shallot local genotypes. Metabolite data had been transformed to $\log 2$ and mean-centered.

Shallot genotypes in the same group exhibited a similar metabolite profile, and showed a relevant metabolite variability to another group. This was also confirmed by the different color of each heatmap 
RASĀYAN J. Chem.

Vol. 12 | No. 3 |1418 - 1425| July - September | 2019

column. The intensity of specific metabolite was visualized on each genotype column with a bright green color. Hierarchical clustering analysis showed that the genotype had a significant effect on the metabolites composition of the shallot. Each genotype of shallot produces different metabolites that associated to the flowering competency. Hierarchical clustering analysis of shallot metabolites grouped shallot genotypes into three distinct genotypes, in both vernalization treatments (Figure-1 and 2). The result indicated that the presence of specific compounds produced in metabolome processes in the vegetative transition to the reproductive phase in different flowering ability.

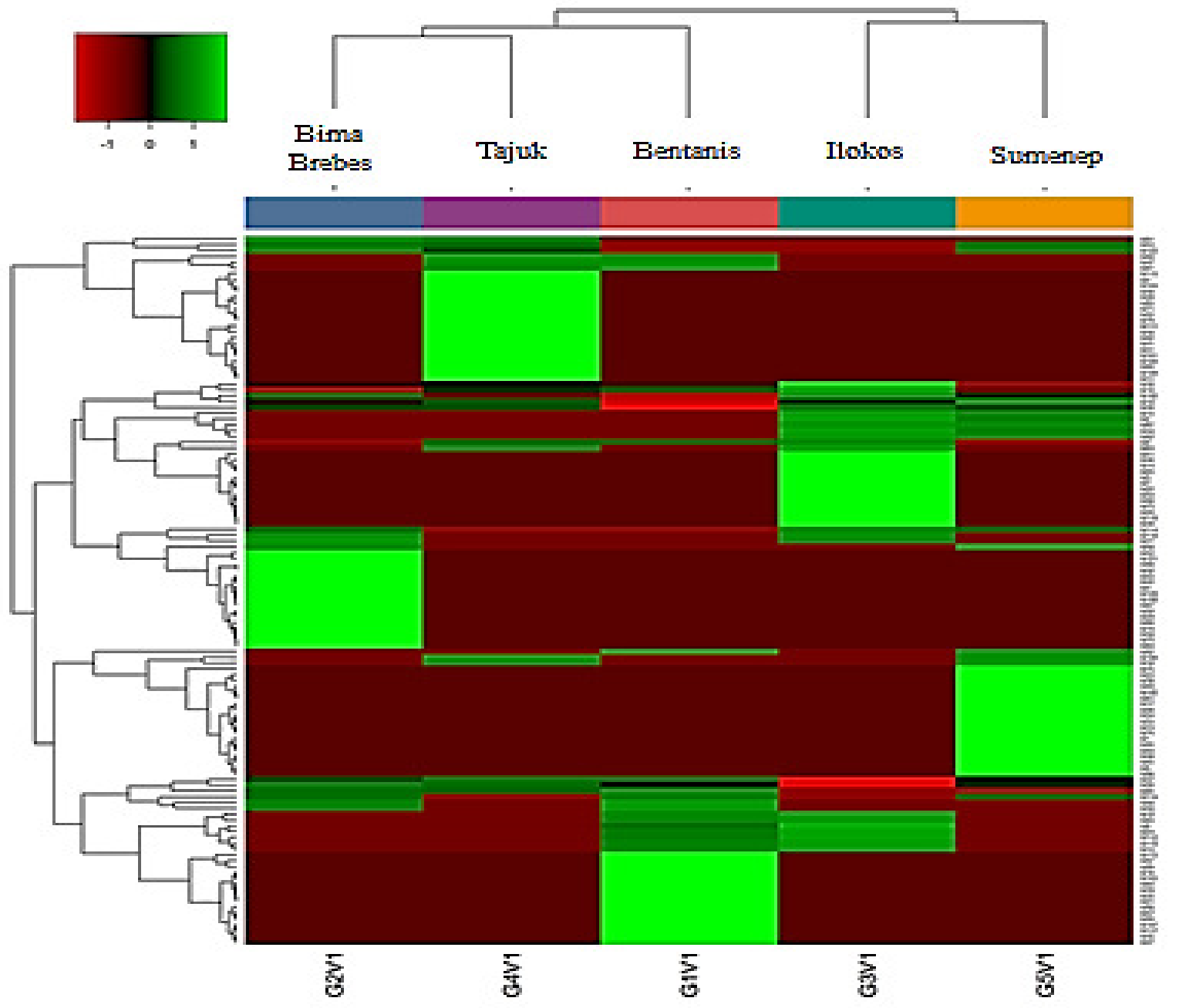

Fig.-2: Heatmap of hierarchical group analysis based on non-targeted metabolomic in 5 shallot local genotypes of 122 metabolites in vernalized bulbs. Color-coded matrix represents the mean values of the metabolite intensity in 5 shallot local genotypes. Metabolite data had been transformed to $\log 2$ and mean-centered

Shallot genotypes located in the same group showed that the genotype had the same metabolite profile, and showed significant metabolite diversity with other groups. Visualization with heatmap also confirmed in the presence of different colors from each of the heatmap columns. The genotypes included in the first group were the Bentanis genotype (G1). In the second group, there was the Bima Brebes (G2) and Tajuk genotype (G4), while in the third group there was Ilokos (G3) and Sumenep genotype (G5). The Bentanis genotype separates on its own group, and has close proximity to the Bima Brebes and Tajuk groups. These three genotypes are genotypes that have the ability to generate interest (sensitive to flowering).

Visualization with heatmap is widely used in metabolomic research because it can visualize large amounts of metabolomic data and classify it in sample groups ${ }^{22}$. intensities of a specific metabolite of each sample of onion are visualized on each genotype column in bright green color.

Mass spectrometry methods can accurately detect compounds including identification of unknown and 
unexpected compounds ${ }^{19}$. Identification of the molecular structure is often given without reference compounds, making it difficult to make a real identification ${ }^{19}$. The genotypes of shallot that have the ability to produce flowers will produce the specific metabolite compounds. Metabolite compounds produced in the transition process of vegetative to generative stage can be an indicator to determine the ability of flowering in shallot. The distribution of metabolomic compounds produced in non-vernalized shallot genotypes is presented in Figure-3.

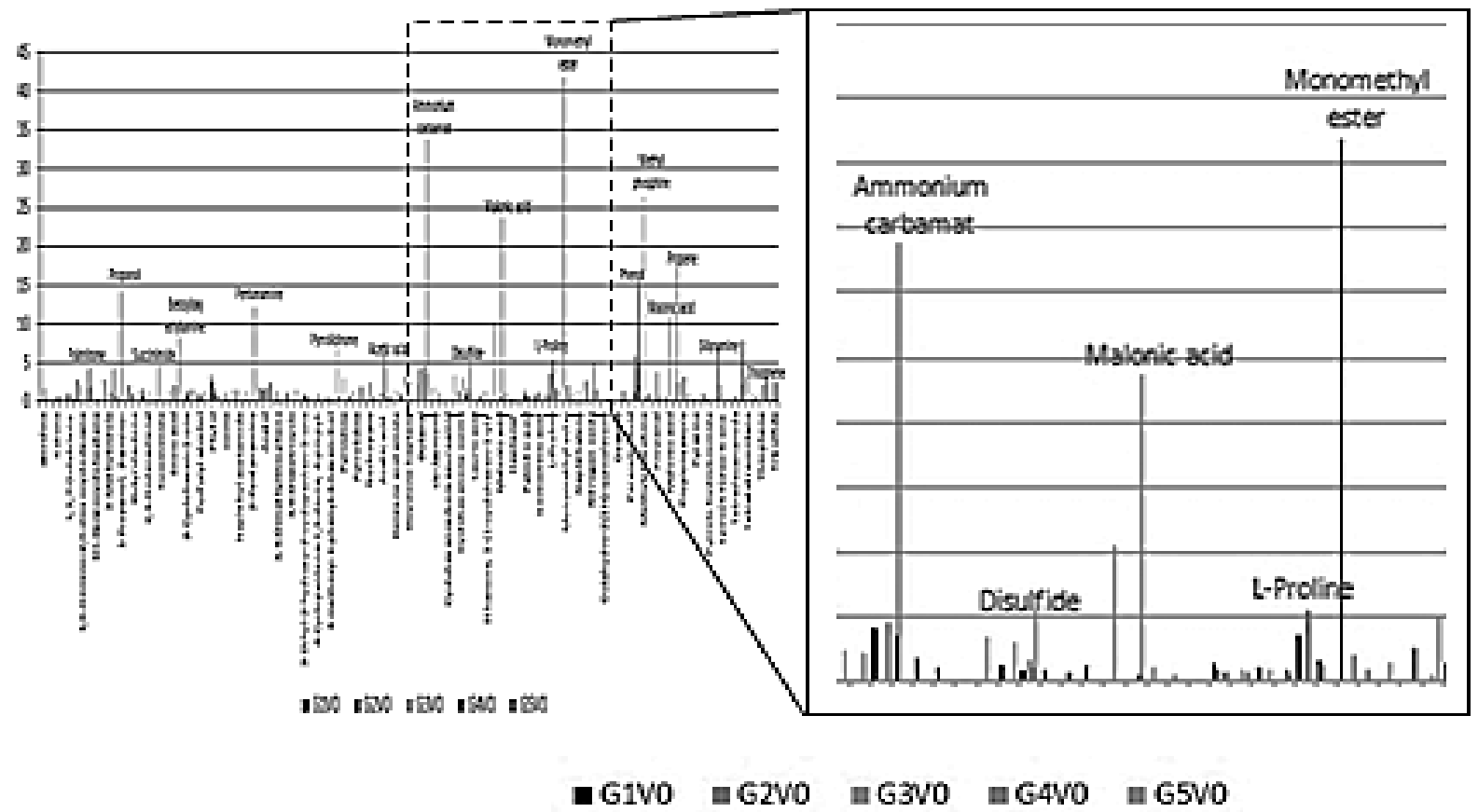

Fig.-3: Metabolite composition in non-vernalizedshallot genotypes. Genotype Bentanis (G1), Bima Brebes (G2), Ilokos (G3), Tajuk (G4) and Sumenep (G5)

The results showed each genotype produced different metabolite compound. In Bentanis genotype showed the presence of monomethyl ester (41.82\%) higher than Sumenep genotype (2.12\%). The monomethyl ester compound, in the form of $\mathrm{Mg}$-protoporphyrin IX mono-methyl ester cyclase is the catalyst required for the oxidation process of chlorophyll formation in plants ${ }^{23}$. The Bentanis genotype growsfaster than Sumenep genotype. Bentanis genotype has robust maximum vegetative growth compared to Sumenep genotype at 5 weeks after planting.Morp hological investigation showed that Bentanis genotype was higher $(36.96 \mathrm{~cm})$ than of Sumenep genotype $(29.82 \mathrm{~cm})$. The presence of monomethyl ester (Mg-protoporphyrin IX mono-methyl ester cyclase) compounds can increase the formation of chlorophyll more optimally, thus increasing the photosynthesis process for the Bentanis genotype growth.

GCMS analysis showed a low concentration of proline $(3.55 \%$ and $5.56 \%)$ was produced in Bentanis and Tajuk genotypes (Figure-3). Proline compounds are generally produced by plants as their responseto stress condition.Bentanis genotype was also produced succinimide compounds at about $4.78 \%$, those can not be found in other genotypes. Succinimide compounds are used as intermediate compounds in the process of forming organic compounds that stimulate plant growth.

The presence of high concentrate of ammonium carbamate compound is found in Bima Brebes genotype. Ammonium carbamate is an important compound in the formation of carbamoyl phosphate and the formation of ATP into $\mathrm{ADP}^{24}$. While the presence of disulfide (dipropyl disulfide) compounds was found higher in non-sensitive flowering genotypes, such as Ilokos and Sumenep (1.69\% and 5.43\%), compared with other genotypes $(0.8-0.14 \%)$. The content of dipropyl disulfide is an important component of activity as an antimicrobial and antioxidant and gives a distinctive aroma to shallot plant. The sulfur compounds indipropyl disulfide is important the components of these metabolite compounds ${ }^{25}$.The sulfur compounds are known to have important activities as antimicrobials and antioxidants ${ }^{26,27}$. Derivative 
products of allicin compounds such as diallyl disulfide, diallyl trisulfide found in garlic essential oil indicate activity as a good antimicrobial ${ }^{28}$.Onion bulbs had the highest concentrations of propanethiol compounds having an aroma 20 times higher than dipropyl disulfide compounds ${ }^{29}$. It also found in nonflowering shallot plant, Ilokos and Sumenep genotypes, they produce higher acetic acid compounds (1.04\% and 5.98\%) compared to the flowering type, the Bentanis genotype (1.02\%).

Utilization of sensitive instruments in the metabolomic analysis is an important way to detect the content of plant essential compounds. Plant metabolites consist of highly diverse chemical compounds ranging from inorganic compounds to hydrophilic, volatile alcohol and ketone compounds, amino and non-amino acids, hydrophobic lipids, and complex natural products ${ }^{19}$.

Utilization of mass spectrometry technology is a great way to solve research and analysis problems in the metabolomic field ${ }^{19}$. Metabolomic analysis was succesfully to identify potential compounds extracted directly from shallot genotypes. Th e results showed higher concentrations of acyclic ditherphene alcohol (phytol) compounds in flowering type shallot, Bentanis genotype (8.23\%), Bima Brebes $(2.2 \%)$ and Tajuk (7.52\%) than the Ilokos genotype (1.15\%) and Sumenep (2.19). The phytol compounds is an indication that vernalization treatment has a positive effect in inducing flowering of shallot genotypes, explaining that these three genotypes are sensitive to vernalization treatment to induce flower formation.Phytol compound is a compound that serves as a precursor of vitamin $\mathrm{E}$ and $\mathrm{K}$. The content of these vitamins plays an important role in the plant body as an enzymatic cofactor in the process of metabolism that stimulates rea productive response. The content of vitamin $\mathrm{E}$ in the form of tocopherol is an important compound as one of the factors in the context of a cellular antioxidant system ${ }^{30}$. The differences of metabolite profile might play a key role in flowering initiation in shallot.

In flowering type of shallot genotypes, Bentanis, Bima Brebes and Tajuk also showed the formation of nitrogen oxide and semicarbazid hydrochlorid which are relatively lower than the non-flowering type, Ilokos and Sumenep. Nitrogen compound is a compound that plays an important role in the vegetative phase of the plant. Once the plant enters the reproductive phase, the nitrogen compounds in the plant body will decrease. In contrast, the Ilokos and Sumenep genotypes show the formation of high nitrogen compounds ie ammonium compounds ammonium carbamat, and nitrogen oxide. The high content of nitrogen compounds in Ilokos and Sumenep genotypes explains that these two genotypes are not sensitive to vernalization treatment, thus not encouraging the flowering formation.

The results also showed that the Sumenep genotype contained high organosulfur compounds compared with other genotypes, namely thiophene $(2.31 \%)$ and trisulfide $(4.25 \%)$. The organosulfur is an important compound in giving aroma and spiciness upsurge in shallot, and play an important role as an antioxidant. Essential compounds in Allium have strong antioxidant ability. Tests on antimicrobial activity showed that all essential oils on Allium were able to inhibit the activity of gram-positive and gram-negative bacteria ${ }^{9}$.

Vernalization treatment triggered in the formation of proline compounds in the Sumenep genotype. Vernalization treatment provides a stress condition to the plants that increase the plant mechanism of adaptation by producing proline compounds. Proline accumulation in the plant body is a physiological response to stress, and as a generative tissue development ${ }^{31}$. Secondary metabolite is the cellular response in plant that receives external pressure.

The metabolite profile of 5 local onion genotypes is also rich in non-volatile phytonutrients, especially the content of phenolic compounds (phenol, 2-propenamide, 3-pyridinamine, $\mathrm{N}$-furfurylidene 2-phenylethyl amine, pyrrolidinedione), amide compounds aziridine-2-carbothioic acid amide) and protein compound (pyroglutamic acid).The essential components, mono and sesquiterpenes, carbohydrates, phenols, alcohols, ether, aldehydes and ketones, are responsible for biological activity and also for their fragrance $^{32}$. Phenols and polyphenol compoundsplay important roles as antioxidants in plants $33,34,35$ .Research on Allium rotundum showed the presence of antioxidant activity of phenol compounds with high concentrations of up to $4 \%^{12}$. Onion extract contained the highest of phenol content, at $17.18 \mathrm{mg}$ GAE per gram of fresh weight ${ }^{36}$, and a phenol content of $114.70 \mathrm{mg}$ GAE per $100 \mathrm{~g}$ of different onion samples $^{37}$. Metabolite compound is the difference among shallot genotypes. Each plant genotype performs metabolic activities that depend on their genetic conditions and the ability to adapt to its environment. The plant biological activity may imply to the proportion of metabolite containing a plant. 
RASĀYAN J. Chem.

Vol. 12 | No. 3 |1418 - 1425| July - September | 2019

\section{CONCLUSION}

A secondary metabolite of 5 genotypes shallot was difference under vernalization treatment. Each genotypes produce different specific metabolites which is clustered according to the flowering competency.A high concentration ditherpene alcohol (phytol) found in flowering-sensitive genotypes (genotype of Bentanis, Bima Brebes and Tajuk), with a lower content of proline and nitrogen (ammonium carbamate and nitrogen oxide).While, in flowering-nonsensitive genotypes(genotype Ilokos and Sumenep) were found a higher level of organosulfur compounds (thiophene and trisulfide). Vernalization treatment caused the Sumenep genotype produces the highest proline compound among other genotypes.

\section{ACKNOWLEDGMENT}

This research is supported by grants from National Innovation System Research Incentive 2016, Ministry of Research, Technology, and Higher Education, Indonesia.

\section{REFERENCES}

1. F.V. Golubev, N.A. Golubkina, and Y.N. Gorbunov, Appl. Microbiol. Biotechnol.,39(5), 532(2003), DOI: $10.1023 / \mathrm{A}: 1025465106772$

2. G. Griffiths, L. Trueman, T. Crowther, B. Thomas, and B. Smith, PTR, 16(7), 603(2002), DOI: 10.1002/ptr.1222

3. T. Ritsema , and S. Smeekens, Curr. Opin. Plant Biol., 6(3), 223(2003)

4. H. Mohammadi-Motlagh, A. Mostafaie, and K. Mansouri, Arch. Med. Sci., 1, 38(2011)

5. Marlin, A. Maharijaya, A. Purwito, and Sobir, SABRAO J. Breed. Genet., 50(3), 313(2018).

6. E.J. Finnegan, D. Bagnall, C. Helliwell, D. Rouse, C. Sheldon, M. Tadege, W.J. Peacock, and E. Dennis, Vernalization, Encyclopedia of Life Sciences Macmillan Publishers Ltd, Nature Publishing Group(2001)

7. J. Song, A. Angel, M. Howard, and C. Dea, J. Cell Sci., 125 (16), 3723(2012).

8. Y. Iijima, Metabolite, 4, 699(2014).

9. D. Mnayer, A. Fabiano-Tixier, E. Petitcolas, T. Hamieh, N. Nehme, C. Ferrant, X. Fernandez, and F. Chemat, Molecules, 19, 20034(2014).

10. H. Xiao, and K. L. Parkin, Phytochem., 68(7), 1059(2007).

11. M.A. Vazquez-Prieto, and R.M. Miatello, Mol. Asp. Med., 31(6), 540(2010).

12. A.A. Dehpour, M. Yousefian, S.A. Jafary Kelarijani, M. Koshmoo, S. Mirzanegad, V. Mahdavi, S.E. Mousavi, E. Shirzad, M. Afzali, M.J. Javad Bayani, J.E. Olyaei, and M.K. Yahyapor, Adv. Environ. Biol., 6(3), 1020(2012).

13. V. Lanzotti, F. Scala, and G. Bonanomi, Phytochem Rev., 13, 769(2014).

14. N. Martins, S. Petropoulos, and I.C.F. Ferreira, Food Chem., 15(211), 41(2016).

15. R.Y. Galingging, Sobir, S.I. Aisyah, and A. Maharijaya, Rasayan J. Chem., 11(2), 575(2018), DOI: 10.7324/RJC.2018.1123001

16. O. Fiehn, Plant Mol. Biol., 48, 155(2002).

17. H. Wu, O.J. Gu, S. Chen, X. Liu, Y. Zhou, X. Zhang, and X. Xu, J. Pharm. Biomed. Anal., 72, 267 (2013).

18. T. Soininen. Ph.D. Thesis, University of Eastern Finland. Finland (2014).

19. S.G. Villas-Boas, S. Mas, M. Akesson, J. Smedsgaard, and J. Nielsen, Mass Spectrom. Rev., 24, 613(2005).

20. P.P. Durgawale, S.A. Hendre, and R.S. Phatak, Rasayan J. Chem., 8(3), 271(2015).

21. N.C.J.P. Lekshmi, S. Viveka, M.B. Viswanathan, G. Manivannan, and T.M. Shobi. Nanobio Pharma. Tech. (2014), DOI: 10.13140/2.1.3278.7523.

22. S.M. Huang, W. Toh, P.I. Benke, C.S. Tan, and C.N. Ong, Metabolomics, 10, 1084(2014).

23. Y.S. Wong, and P.A. Castelfranco, Plant Physiol.,79(3), 730(1985).

24. N. Baker, J. Harbinson, and D.M. Kramer, Plant Cell Environ.,30, 1107(2007)

25. P. Rattanachaikunsopon, and P. Phumkhachorn, Afr. J. Microbiol. Res., 3, 747(2009).

26. A. Chehregani, F. Azimishad, and A.H. Haj, Int. Agri. Biol., 9(6), 873(2007)

27. C.L. Ye, D.H. Dai, and W.L. Hu, Food Control,30, 48(2013).

1424 
RASĀYAN J. Chem.

Vol. 12 | No. 3 |1418 - 1425| July - September | 2019

28. J.W. Kim, J.E. Huh, S.H. Kyung, and K.H. Kyung, Food Sci. Biotech., 13, 235(2004).

29. M.M. Lokke, M. Edelenbos, E. Larsen, and A. Feilberg, Sensors,12, 16060(2012).

30. M.G. Traber, J. Atkinson, and Atkinson, Free Radical Biol. Med., 43(1), 4(2007).

31. N. Verbruggen, and C. Hermans, Amino Acids, 35, 753(2008).

32. E.A. El-Wakil, M.M. El-Sayed, and E.E. Abdel-Lateef, Int. J. Pharma Sci. Res.,6(3) (2015).

33. S.A.B.E. Van Acker, D.J. van den Berg, N.J.L. Tromp, D.H. Griffioen, W.P. van Bennekom, and W.J. van der Vijgh, Free Radical Biol. Med., 20(3), 331(1996).

34. M.A. Alvarez, N.B. Debattista, and N.B. Pappano, Folia Microbiol., 53(1), 23(2008).

35. A.P. Mukne, V. Viswanathan, and A.G. Phadatare, Pharmacognosy Rev., 5(9), 13(2011)

36. X. Lu, J. Wang, H.M. Al-Qadiri, C.F. Ross, J.R. Powers, J. Tang, and B.A. Rasco, Food Chem.,129, 637(2011).

37. J. Yang, K.J. Meyers, J. van der Heide, and R.H. Liu, J. Agr. Food Chem., 52, 6787(2004).

[RJC-4034/2018] 